\title{
THE PREVALENCE AND SPECTRUM OF MYCOBACTERIUM TUBERCULOSIS CHEMORESISTANCE AMONG TB PATIENTS
}

\author{
ARIADNA PETRONELA FILDAN ${ }^{1 \#}$, IOAN ANTON ARGHIR ${ }^{2 *}$, GEORGETA GILDA POPESCU ${ }^{3 *}$, \\ CLARA MATEI $^{4}$, ROXANA MARIA NEMES ${ }^{3}$, DOINA TOFOLEAN ${ }^{1 \#}$, ELENA DANTES $^{1}$, \\ CORINA SILVIA POP ${ }^{5}$, SIMONA CLAUDIA CAMBREA ${ }^{1}$
}

${ }^{1}$ Faculty of Medicine, “Ovidius” University of Constanța, 124 Mamaia Boulevard, 900527, Constanța, Romania

${ }^{2}$ Pulmonology Department, "Sf. Andrei” Clinical Emergency Hospital, 145 Tomis Boulevard, 900591, Constanța, Romania

${ }^{3}$ Pulmonology Department, "Marius Nasta" Hospital, 90 Viilor Road, 050152, Bucharest, Romania

${ }^{4}$ Department of Dermatology, "Carol Davila” University of Medicine and Pharmacy, Bucharest, Romania

${ }^{5}$ Department of Internal Medicine, "Carol Davila” University of Medicine and Pharmacy, Bucharest, Romania

\author{
*corresponding author: popescugilda@yahoo.com \\ ${ }^{\#}$ Authors with equal contribution.
}

Manuscript received: March 2019

\begin{abstract}
Rapid detection of Mycobacterium tuberculosis (MTB) chemoresistance against anti-tuberculosis drugs is a major challenge of any Pulmonology department. The aim of the study was to synthesize the epidemiological features of multidrug resistant (MDR), rifampicin resistant (RR) or extensively drug resistant (XDR) TB, for estimating the extent of MTB resistance pattern and severity of tuberculosis (TB) disease. Between $1^{\text {st }}$ of March 2013 to $31^{\text {st }}$ of December 2017, all 1,643 inpatients with positive diagnosis of pulmonary TB active disease were evaluated by specific methods consisting in phenotypic and genotypic investigation of MTB strains. The frequency and pattern of MTB resistance to anti-TB drugs were assessed. The prevalence of MDR-TB was low (1.95\%). Delayed diagnosis of MDR-TB was frequent $(71.87 \%)$ and more common in active smokers $(53.12 \%)$, unemployed and uninsured patients. The secondary pattern of chemoresistance was prevalent $(62.5 \%)$, but primary resistance pattern of MTB was related to younger individuals mean aged 38 years $(\mathrm{p}<0.03)$. The prevalent broad- spectrum of MTB resistance against first line of anti-TB drugs was noticed in majority of cases $(87.5 \%)$, with the predominance of isoniazid $(\mathrm{H})$ and rifampicin $(\mathrm{R})$ pattern $(53.1 \%)$, and supplementary gaining XDR profile. Although MDR-TB prevalence was low and HR pattern dominated the spectrum of MTB resistance, the progressive extension of MDR to XDR profile of resistance occurred.
\end{abstract}

\section{Rezumat}

Detectarea rapidă a chimiorezistenței dezvoltate de Mycobacterium tuberculosis (MTB) la medicamentele antituberculoase este o provocare majoră pentru orice departament de pneumologie. Scopul studiului a fost evaluarea caracteristicilor epidemiologice ale tuberculozei multirezistente (TB-MDR), rifampicin rezistente (RR) sau extensiv rezistente (XDR), necesitând conturarea profilului chimiorezistenței și severității bolii tuberculoase. Intre 1 Martie 2013 si 31 Decembrie 2017 , toate cazurile de TB pulmonara spitalizate si confirmate bacteriologic $(n=1.643)$ au fost evaluate prin metode fenotipice si genotipice. Au fost determinate frecvența și profilul chimiorezistenței MTB. Prevalența TB-MDR a fost scăzută $(1,95 \%)$. Diagnosticul TB-MDR a fost frecvent tardiv (71,87\%), mai ales la fumătorii activi $(53.12 \%)$, persoane neasigurate și fără ocupație. Modelul chimiorezistenței secundare al MTB predomină (62,5\%), iar chimiorezistența primară se asociază cu vârsta medie tânără (sub 38 ani) a adulților ( $<<0,03$ ). Prevalența crescută a chimiorezistenței la medicamentele antiTB de prima linie a fost observată la majoritatea cazurilor $(87,5 \%)$, cu predominanța rezistenței la izoniazidă $(H)$ și rifampicină $(R)$ $(53,1 \%)$ și dobândirea chimiorezistenței extensive (XDR). Deși prevalența TB-MDR e redusă și HR domină spectrul chimiorezistenței, survine extensia progresivă de la MDR la XDR.

Keywords: tuberculosis, Mycobacterium tuberculosis, chemoresistance, MDR-TB, XDR-TB

\section{Introduction}

Drug resistant tuberculosis (DR-TB) forms of active disease represent a serious public health threat, with an incidence and mortality continuously growing worldwide. The resistant pattern of Mycobacterium Tuberculosis (MTB) strains to the drugs used to treat the disease can be achieved by an incorrect or inappropriate administration of antiTB drugs, in terms of association, dosage, or duration. DR-TB can be acquired through person to person transmission, or through deficient management of TB treatment. Multidrug resistant (MDR) TB is more difficult to treat than drug-susceptible $\mathrm{TB}$, requiring much longer and more expensive therapies with a higher rate of adverse events and even mortality. In 2016, globally, approximately 600.000 persons developed MDR or 
FARMACIA, 2020, Vol. 68, 1

rifampicin resistant (RR) TB, and $6.2 \%$ of MDRTB cases had additional drug-resistance, known as extensively drug-resistant (XDR) TB [1]. In Romania, in 2015 , there were 14.225 notified TB cases, of which $4.8 \%$ oо were MDR/RR-TB cases [2]. Although Romania made substantial improvements in diagnosing MDR-TB, the number of notified cases is below the estimated value considered by World Health Organization (between 800 and 1000 new MDR-TB cases) [3]. The main reason of this discrepancy is represented, from time to time, by partial and intermittent testing of the bacteriologically confirmed TB cases and lack of necessary equipment. Considering the negative impact of TB drug resistance phenomenon on the treatment efficiency, with direct consequence on spreading the resistant MTB, the aim of the study was to analyse the epidemiological profile of MTB, defining the primary and secondary type of chemoresistance among TB case-patients in Constanțta County, Romania.

\section{Materials and Methods}

\section{Patients and sample processing}

A prevalence study, approved by the Ethics Committee of Clinical Pneumophthysiology Hospital of Constanțta, Romania, was conducted from January $1^{\text {st }}$ of 2013 to December $12^{\text {th }}$ of 2017 , using the electronic database of all notified TB in patients $(n=1,643)$. TB diagnosis was sustained by positive sputum smears and cultures. Inclusion criteria consisted in the evidence of Mycobacterium tuberculosis resistant strains against rifampicin (R) and/or isoniazid (H). All patients signed an informed consent before enrolling in the study.

Identification tests of multidrug resistant forms of TB The identification tests of multidrug resistant forms of TB needed genetic and phenotypic methods with mandatory drug testing (DST), which were recommended in accordance with national and international guidelines (two sputum specimens were collected from each patient and then processed for TB diagnosis by smear microscopy and culture) [4-7]. Each sputum sample was decontaminated using sodium hydroxide method, followed by neutralization and centrifugation. Sediment was examined by Ziehl-Neelsen staining and cultured in Löwenstein-Jensen slope and/or into a Mycobacteria Growth Indicator Tube (MGIT), according to the manufacturer's instructions (BACTEC MGIT 960 system BD Diagnostics Systems, Sparks, MD).

Drug sensitivity testing

The resistance against rifampicin $(\mathrm{R})$ and/or isoniazid $(\mathrm{H})$ was tested using the rapid detection molecular tests, such as Xpert MTB/RIF (Cepheid, Sunnyvale, CA, USA) and a rapid line probe assay (LPA) (Hain Lifescience GmbH, Nehren, Germany). All subcultures showing drug resistance of MTB to HR were later transported to the national reference laboratory in Bucharest for an extensive DST to pyrazinamide, ethambutol, streptomycin, ethionamide, ofloxacin, para-aminosalicylic acid, and to the secondline injectable drugs (amikacin, kanamycin and capreomycin). HR resistance was defined as resistance revealed either by the rapid molecular tests or the conventional culture-based susceptibility test. According to the international [8] and national [9] guidelines, all definitions were considered: primary (initial) resistance of MTB if resistance was detected in TB patients who had never received, or received under one month of any anti-tuberculosis treatment; secondary (acquired) resistance of MTB, if resistance was detected in previously treated cases with more than 1 month prior to the detection of the resistance; mono drugresistance (DR) when resistance to a single anti-TB drug is determined (excluding Rifampicin resistance -RR- which represents a special form of monoresistance, considered a prior form of MDR, whereas in $85 \%$ of cases it can also associate resistance to isoniazid); multidrug resistant tuberculosis (MDRTB) defined as resistance to both HR; and extensively drug resistant tuberculosis (XDR-TB) defined as MDR-TB with additional fluoroquinolone and secondline injectable agent resistance.

Statistical analysis

Data on demographics, previous TB exposure or treatment, risk factors, clinical and radiological features, bacteriological status, comorbidities and evolution under anti-TB treatment were recorded and analysed, including multivariate logistic regression models by IBM SPSS Statistics version 19.

\section{Results and Discussion}

During the study period of almost 4 years, 1,643 patients were hospitalized and diagnosed with pulmonary active TB disease (PTB), of which 32 were identified with different drug resistant strains of MTB. The overall prevalence of hospitalized MDR-TB was low (1.95\%), with higher values of new cases and relapses in 2016 (Figure 1). This value is lower than those reported by a Brazilian study, that involved 2176 patients diagnosed with pulmonary TB between 2000-2004 in the city of Santos, Brazil, where the drug resistant TB was found in $15 \%$ of the cases, mostly on males $(78 \%)$ and with a lower median age at diagnosis (39.2 versus 47 years) [10].

Demographic, clinic and radiologic features of MDR-TB patients revealed a mean age of $47 \pm$ 15.14 years and an increased prevalence $(46.8 \%)$ among cases between 40 and 59 years. MDR-TB disease occurred more frequently in males $(71.8 \%)$, smokers and former smokers $(68.75 \%)$, uninsured (46.9\%) and people living in urban areas $(62.5 \%)$ (Table I). 


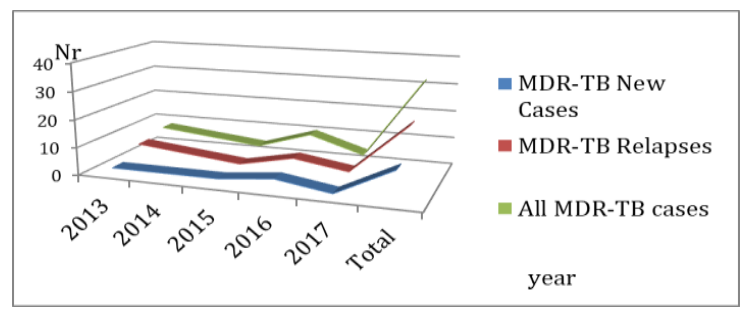

Figure 1.

The distribution of annually hospitalized MDR-TB by epidemiological categories of disease (new cases and relapses)

Table I

Demographic, clinic and radiologic features of MDR-TB patients

\begin{tabular}{|c|c|}
\hline Characteristics & MDR-TB patients $(\mathrm{n}=, \%)$ \\
\hline Total & $32(1.95)$ \\
\hline Gender & \\
\hline male & $23(71.87)$ \\
\hline female & $9(28.12)$ \\
\hline Age (mean) & $47 \pm 15.14$ \\
\hline Residence & \\
\hline urban & $20(62.5)$ \\
\hline rural & $12(37.5)$ \\
\hline Exogenous risk factors* & $17(53.12)$ \\
\hline Smoking status & \\
\hline smokers \& ex-smokers & $22(68.75)$ \\
\hline non-smokers & $10(31.25)$ \\
\hline Constitutional symptom & \\
\hline cough & $7(21.87)$ \\
\hline hemoptysis & $1(3.1)$ \\
\hline fever & $1(3.1)$ \\
\hline night sweats & $3(9.37)$ \\
\hline body weight loss & $4(12.5)$ \\
\hline nausea, vomiting & $2(6.25)$ \\
\hline Comorbidities & \\
\hline Diabetes mellitus & $2(6.25)$ \\
\hline Cardiovascular diseases & $5(15.62)$ \\
\hline COPD & $2(6.25)$ \\
\hline Bronchiectasis & $2(6.25)$ \\
\hline Chronic liver disease & $2(1.6)$ \\
\hline Radiological appearances & \\
\hline cavitation & $14(43.75)$ \\
\hline nodules & $5(15.62)$ \\
\hline ulceration & $13(40.62)$ \\
\hline
\end{tabular}

* poor living conditions, homeless, institutionalized patients or not having medical insurance

The symptoms of TB are variable, generally nonspecific, but closely related to the extent, location and character of the TB lesions, as well as aggravated comorbidities. Due to the fact that the MTB has a slow rate multiplication, the onset is frequently insidious, with a gradual deterioration of the health status. The main manifestations, such as weight loss, low fever, nocturnal sweating, fatigue, and persistent cough, were present in $87.5 \%$ of patients (Table I), similar to other reported studies [10-12]. The clinical manifestations of pulmonary MDR-TB had an insidious pattern of the onset $(78.1 \%)$. The most common radiological appearance of PTB included cavities $(43.75 \%)$ and ulcerated lesions $(40.62 \%)$ (Table I) and, in $71.4 \%$, of cases the size of cavitary lesions was $\geq 4 \mathrm{~cm}$. Previous published data [10, 13] documented an association between the clinical suspicion of anti-TB drug resistance and the presence and persistence of a greater number of pulmonary cavitary lesions. Drug resistant TB represents, all over the world, even in countries with a low burden of TB [14], a significant health problem and a real epidemiological challenge in obtaining reliable information on the real prevalence and spectrum of MTB resistant strains among TB patients. Delayed diagnosis of $\mathrm{TB}$ and/or severe comorbidities can have an important unfavourable impact on the survival [15-17]. In the particular case of MDR-TB, the delayed diagnosis of MDR-TB can influence dramatically the outcomes of any TB control program. 
FARMACIA, 2020, Vol. 68, 1

Most of the patients $(n=23 / 32 ; 71.87 \%)$, had any known exposure to a TB source of infection. Almost a third of MDR-TB patients $(n=9 / 32$; $28.1 \%$ ) were actively diagnosed within the contact investigation of TB patients previously identified (3 of them being in contact with MDR-TB patients). A third of MDR-TB cases $(\mathrm{n}=11 / 32 ; 34.37 \%$ ) represented new cases of TB active disease, not previously reported or ever treated. Regarding the history of sensitive TB treated disease, the rest of the cases $(n=21 / 32 ; 62.5 \%)$ received at least once TB treatment (maximum 4 relapses per patient). Non-compliance to previous anti-TB regimens $(\mathrm{n}=$ $11 / 32 ; 34.37 \%)$ and frequent relapses $(n=10 / 32$; $31.25 \%$ ) were the main risk factors for the occurrence of drug resistance phenomenon. The prevalence of smoking exposure $(n=22 / 32 ; 68.75 \%)$ was significantly higher than other comorbidities of TB $(\mathrm{n}=13 / 32 ; 40 \%)\left(\mathrm{OR}=3.154 ; \mathrm{RR}=1.6923 ; \chi^{2}=\right.$ 5.0276, $\mathrm{p}<0.025$ ) (Table I). Regarding the risk factors for the occurrence of drug resistance, our study showed that majority of patients with MDRTB were smokers and former smokers $(68.75 \%)$, similar to a study from Georgia conducted on 591 TB patients, reporting a lower risk of developing MDR-TB in non-smokers and former smokers comparing with active smokers [18]. Smoking is a known risk factor not only for obstructive lung diseases [19] or lung cancer [20], but even for pulmonary $\mathrm{TB}$, and, in the absence of adequate treatment, in terms of dosage, duration, association of drugs, it evolves in severe cavitary forms [21]. New cases of MDR-TB occurred after a large interval of time $72.28 \pm 97.33$ months (range 1 444 months) from the first episode of TB active disease, irrespective of the primary or secondary pattern of resistance. In acquired (secondary) type of MDR-TB, the mean time from the first diagnosis of TB disease until the occurrence of resistance was much higher, of $115.65 \pm 100.879$ months (range 10 to 444 months). The main risk factor for the

secondary pattern of MDR is the poor adherence to previous TB treatments. In contrast with Coelho's study [11], which showed similar values of primary and secondary resistance, our study showed a higher proportion of acquired resistance $(62.5 \%)$, with a median duration between the first TB diagnosis and appearance of MDR-TB of 72 months, revealing previous deficiencies in administering directly observed therapy. Similar data, documented, in 2016, by WHO Report, revealed approximately $3 \%$ of new cases and $12 \%$ of TB relapses as MDR-TB cases [1].

Patients with primary type of MDR were significantly much younger than those with secondary type, according to ANOVA analysis: $38.36 \pm 11.673$ years (range: 24 - 59 years) compare to $50.9 \pm 15.718$ years (range: $23-83$ years); $\mathrm{F}=5.341 ; \mathrm{p}=0.028$. The quality of life is severely affected, in all independent domains, (physical health, psychological, social and environmental) [22]. In other chronic pulmonary diseases, only the total score of the quality of life was related with the physical indicators [23] Bacteriological exam of sputum specimens revealed the presence of acid-fast bacilli (AFB) in $90.6 \%$ of MDR-TB cases, $96.9 \%$ positive MGIT cultures and $100 \%$ positive Löwenstein-Jensen cultures (solid media). Xpert testing was not available in the first 2 years of study (between 01.01.2013 - 30.09.2014). So, only 21 patients $(65.62 \%)$ were tested and rifampicin resistance (RR) was detected in $85.71 \%$ cases $(n=18 / 21)$. The level of $R R$ revealed by GeneXpert was a moderate one in $84 \%$ of cases. LPA was available for less cases $(\mathrm{n}=18 / 32$; $56.25 \%$ ), but it had a higher rate of HR detection ( $\mathrm{n}$ $=17 / 18 ; 94.4 \%$ ) with an obvious KatG MUT pattern in $82.35 \%(n=14 / 17)$ Overall, using drug sensitivity testing (DST), by both phenotypic and genotypic tests results, the MTB resistant spectrum was polymorphic with the predominance of resistance to the first line antiTB drugs $(n=28 / 32 ; 87.5 \%)$, mostly double HR profile of resistance $(\mathrm{n}=17 / 32$; $53.1 \%$ ) (Table II).

Table II

The distribution of the initial MDR profile of resistance

\begin{tabular}{|c|c|c|}
\hline Initial Drug Sensitivity Testing & Nr. of cases & $(\%)$ \\
\hline INH+ RMP & 17 & $53.1 \%$ \\
\hline INH+ RMP+ EMB+ SM & 3 & $9.4 \%$ \\
\hline INH+ RMP+ EMB+ PZA+ SM & 2 & $6.3 \%$ \\
\hline INH+ RMP+ EMB & 2 & $6.3 \%$ \\
\hline INH+ RMP+ SM & 2 & $6.3 \%$ \\
\hline INH+ RMP+ PZA+ SM & 1 & $3.1 \%$ \\
\hline INH+ RMP+ EMB+ PZA & 1 & $3.1 \%$ \\
\hline INH+ RMP+ PAS & 1 & $3.12 \%$ \\
\hline INH+ RMP+ EMB+ OFX & 1 & $3.1 \%$ \\
\hline INH+ RMP+ SM+ KM & 1 & $3.1 \%$ \\
\hline INH+ RMP+ SM+ KM+ AK & 1 & $3.1 \%$ \\
\hline Total cases & 32 & $100 \%$ \\
\hline
\end{tabular}

$\mathrm{INH}=$ isoniazid, $\mathrm{RMP}=$ rifampicin, $\mathrm{PZA}=$ pyrazinamide, $\mathrm{EMB}=$ ethambutol, $\mathrm{SM}=$ streptomycin, $\mathrm{KM}=\mathrm{kanamycin} ; \mathrm{AK}=\mathrm{amikacin} ; \mathrm{OFX}$ $=$ ofloxacin PAS $=$ para-aminosalicylic acid 
Accessibility to rapid phenotypic and genotypic tests facilitates an early diagnosis of MDR-TB [24]. In the present study, the accessibility to fast methods of detection of drug resistance was increased for the BACTEC MGIT method ( $\mathrm{n}=$ $31 / 32$; 96.9\%), but lower for molecular methods (between 56.2 and 65.6\%). Molecular tests cannot be substituted of phenotypic ones, but may be useful in the screening of MTB and anti-TB drug resistance, as well as in the identification of silent mutations that are not identified by phenotypic methods and are considered to be false-positive [24]. The accessibility to Xpert testing was higher ( $\mathrm{n}=21 / 32 ; 65.6 \%$ ), but with more frequent negative outcomes $(\mathrm{n}=3 / 21 ; 14.9 \%)$, compared to LPA genotyping, which showed positive results in the majority of tested patients $(\mathrm{n}=17 / 18 ; 94.4 \%)$. BACTEC MGIT 960 is extremely important due to the possibility of drug susceptibility testing (DST) for both the first and the second line of anti-TB drugs [25]. In this study, the results regarding MTB distribution pattern of resistance are similar with those identified in the north-eastern part of Romania [25], where the MDR pattern associates additional resistance to the second line of anti-TB medication. A lower proportion of MDR patients included in this study (9.4\%) developed XDR, compared to the study of Lunca et al. [26], where $17 \%$ of MDR patients developed XDR. A study conducted in the Romanian National Pulmonology Institute of Bucharest, involving a large number of molecular tests (872 LPA and 1,580 GeneXpert), reported MTB detection in $88.64 \%$ of LPA testing with 126 cases diagnosed with MDR-TB, while $19.87 \%$ of GeneXpert tests detected MTB, of which 14 cases were MDR-TB [27].

Evolution under treatment was generally favourable for $84.37 \%$ of patients $(n=27)$, only 3 patients developed, during the 4-year study, an extension of MDR pattern to acquired resistance to ofloxacin (floroquinolone) and amikacin (a second-line injectable anti-TB drug), representing XDR-TB new cases. In one case the treatment failed and another one was considered a chronic form of MDR-TB. Sometimes, surgical therapy is required for resolving MDR-TB cases [28]. Considering the high burden of TB in Romania [29], a properly performed bacteriological exam can facilitate the early diagnosis and therapy of new cases of MDRTB. Reducing the impact of human errors and increasing the adherence to standardized regimens of therapy, the occurrence of MDR-TB can be prevented. Without a sustained supervision of administration and periodic monitoring of adequate anti-TB treatment and therapeutic adherence, the extent of MDR can lead to XDR forms of TB disease.

\section{Conclusions}

The prevalence of hospitalized MDR-TB was $1.95 \%$, with the predominance of acquired resistance pattern. The spectrum of MTB resistance was dominated by the HR pattern, with progressive extension of MDR to XDR profile of resistance. MDR-TB occurrence and extension can be prevented by rapid new molecular methods of diagnosis and a better adherence to therapy.

\section{Conflict of interest}

The authors declare no conflict of interest.

\section{References}

1. ***World Health Organization Report, WHO/HTM/2016.13. Geneva (available at www.who.int).

2. $* * *$ http://insp.gov.ro.

3. ***ECDC Surveillance Report Tuberculosis, 2015 (available at https://ecdc.europa.eu).

4. Homorodean D, Moldovan O, Diculencu D, Chiriac G, Muntean I, Guidance on bacteriology laboratory techniques BK, PNCT, Bucureşti, 2005 (available in Romanian).

5. $* * *$ World Health Organization. WHO/HTM/TB/2008.392. Policy guidance on drug-susceptibility testing (ABG) of second-line antituberculosis drugs. Geneva, 2008 (available at www.who.int).

6. $* * * \mathrm{WHO} / \mathrm{TB} / 98.258$, Laboratory Services in Tuberculosis Control (available at https://apps.who.int).

7. Homorodean D, Moisoiu A. Standards for TB laboratories, 2017, available in Romanian at www.ms.ro).

8. *** World Health Organization, 2016. WHO treatment guidelines for drug-resistant tuberculosis 2016 update (available at www.who.int)

9. Miron AB. (coordinator) Methodological guide for the implementation of the National Program for Tuberculosis Prevention, Surveillance and Control. Ed. Alpha MDN, Buzau, 2015: 22 (available in Romanian at http://old.ms.ro).

10. Santos LC, Bousquet HM, Pereira AM, JunqueiraKipnis AP, Kipnis A, A high prevalence of resistance in new tuberculosis cases of midwestern Brazil. Infect Genet Evol., 2010; 10: 1052-1057.

11. Coelho AGV, Zamarioli LA, Telles, MA, Ferrazoli L, Waldman EA, A study of multidrug-resistant tuberculosis in risk groups in the city of Santos, São Paulo, Brazil. Mem Inst Oswaldo Cruz, 2012; 107(6): 760-766.

12. Micheletti VC, Kristski AL, Braga JU, Clinical features and treatment outcomes of patients with drug-resistant and drug-sensitive tuberculosis: A historical cohort study in Porto Alegre, Brazil. PloS one, 2016; 11(8): 1-13.

13. Yang L, Yu X, Lin Y, Yang N, Lu D, Zhang S, Du P, Liu X, Su Y, Zhang H, Liu G, Effect of olanzapine on invasion and metastasis of lung 
cancer cells and the nursing role of patients after chemotherapy. Farmacia, 2018; 66(4): 674-679.

14. Arghir OC, Pereira PMA, Rascu A, Dantes E, Borgazi E, Iliescu DM, Otelea MR, Cambrea SC, Farmacia, 2018; 66(3): 537-540.

15. Arghir OC, Dantes E, Otelea M, Rascu A, Borgazi $\mathrm{E}$, Cambrea SC. The impact of migrant tuberculosis on the chimioresistant pattern of antituberculosis drugs in a low burden TB European country. Rom J Leg Med., 2018; 26(2): 187-191.

16. Dantes E, Tofolean DE, Fildan AP, Craciun L, Dumea E, Tofolean IT, Mazilu L, Lethal disseminated tuberculosis in patients under biological treatment - two clinical cases and a short review. J Int Med Res., 2018; 46(7): 2961-2969.

17. Man MA, Arghir OC, Man S, Streba CT, Olteanu M, Nitu M, Fatal paradoxical cryptic miliary tuberculosis and immune reconstitution disease in a young non- HIV immunocompromised male patient- Case report with autopsy findings. Rom $J$ Morphol Embryol., 2014; 55(2): 453-457.

18. Gegia M, Magee MJ, Kempker RR, Kalandadze I, Chakhaia T, Golub JE, Blumbers HM, Smoking and tuberculosis treatment outcomes: A prospective study in Georgia. Bull. World Health Organ., 2015; 93(6): 390-399.

19. Mihailov C, Jimborean G, Rascu A, Arghir OC, The Impact of tobacco smoke exposure on asthma COPD-like patients. J Environ Prot Ecol., 2016, 17(4): 1523-1533.

20. Doll R, Smoking and lung cancer. Am J Respir Crit Care Med., 2000; 162: 4-6.

21. ***WHO- TB and Tobacco, 2009 (available at www.who.int).
22. Sharma R, Yadav R, Shrama M, Saini V, Koushal $\mathrm{V}$, Quality of life of multi drug resistant tuberculosis patients: a study of north India. Acta Med Iran, 2014; 52(6): 448-453.

23. Otelea MR, Arghir OC, Zugravu C, Naghi E, Antoniu S, Rascu A, Lung function and quality of life in workers with chemical and dust exposure. Rev Chem (Bucharest), 2018; 69(2): 346-349.

24. Robledo J, Mejia GI, Paniagua L, Martin A, Guzman A, Rapid detection of rifampicin and izoniazid rezistence in Mycobacterium tuberculosis. Int J Tuberc Lung Dis., 2008; 12(12): 1482-1484.

25. Rodriguez C, Jani J, Shenai S, Drug Susceptibility testing of $M$. tuberculosis against second-line drugs using Bactec MGIT 960. Int J Tuberc Lung Dis., 2008; 12(12): 1449-1455.

26. Luncă C, Dorneanu OS, Diculencu D, Vremera T, Badescu AC, Olaru SP, Iancu LS, Molecular detection of rifampicin resistance in multidrugresistant Mycobacterium tuberculosis strains from North-Eastern Romania. Rev Rom Med lab., 2013; 21(3/4): 293-299.

27. Mindru R, Spinu V, Popescu O, LPA or GeneXpert in the diagnosis of multidrug-resistant tuberculosis. Pneumologia, 2016; 65(2): 76-80.

28. Man MA, Nicolau D, Surgical treatment to increase the success rate of multidrug-resistant tuberculosis. Eur J Cardiothorac Surg., 2012; 42(1): e9-12.

29. Nitu FM, Olteanu M, Streba CT, Jimborean G, Postolache P, Man MA, Trofor AC, Nemes RM, Dragonu L, Oleanu M, Tuberculosis and its particularities in Romania and worldwide. Rom $J$ Morphol Embryol., 2017; 58(2): 385-392. 